\title{
Free-cooling potential in shopping mall buildings with plants equipped by dry-coolers boosted with evaporative pads
}

\author{
Alessandra De Angelis, Damiana Chinese, Onorio Saro \\ Department Polytechnic of Engineering and Architecture, via delle Scienze, 208, University of \\ Udine, Udine 33100, Italy
}

Email: alessandra.deangelis@uniud.it

\begin{abstract}
Shopping malls are often characterized by high internal thermal loads due to occupancy, lighting, electrical devices, and solar radiation entering through the large skylights. The aim of this study is the evaluation of the energy saving reachable adding a cooling evaporative pad upstream a dry cooler. In particular, two different cooling plant configurations has been investigated: a cooling plant with a chiller equipped with a dry cooler (C-DC), that can be used as condenser of refrigeration system or to work with free-cooling mode and the previous system equipped with an evaporative cooling pad upstream the dry cooler (C-E-DC) in order to enlarge the range of temperatures suitable for free cooling. A building model of a typical shopping mall and two cooling plant has been modeled by means of TRNSYS simulations carried out in several European cities. Simulation results show that the C-E-DC configuration allows a greater energy saving amount than C-DC configuration for all the cities considered. It can be noted that the locations with a hot or moderate climate have a higher reduction in chiller electrical consumptions. Further investigations will be carried out taking in to account more extensively the moisture content of the air for the different locations considered.
\end{abstract}

Keywords: Evaporative Pad, Energy Saving, Free Cooling, TRNSYS, Shopping Mall.

\section{INTRODUCTION}

In recent decades, commercial malls became not only a place where to shop but also a place where to relax and to socialize. People spend a lot of their spare time in shopping mall and new shopping centers are rising all over the city.

The reduction of energy consumptions in existing commercial buildings and the identification of guidelines to support the design of the future shopping centers is becoming a pressing focus. Moreover, the Energy Performance of Buildings Directive requires all new buildings to be nearly zero-energy by the end of 2020 and all new public buildings to be nearly zero-energy by 2018 .

From 2006 to 2014, D'Agostino et al. [1] collected in the framework of the Green Building Programme several data about both new and existing non-residential buildings. They found that non-residential buildings account on average for $25 \%$ energy consumption of the total European building stock [2] and represent a heterogeneous sector compared with the residential [3].

In particular, based on a study of the Buildings Performance Institute Europe [4], among European nonresidential buildings it can be identify three categories: wholesale \& retail (28\%), offices (23\%), educational (17\%), hotels and restaurants $(11 \%)$, hospitals $(7 \%)$, sport facilities
(4\%), other $(11 \%)$ [1].

This sector holds a big percentage of total European final energy consumption, especially in relation to commercial and hospitals buildings [5]. The authors are involved in the CommONEnergy project [6], funded by the European Community Seventh Framework Programme, which has the objective to develop a systematic approach to reduce energy consumptions in shopping malls.

The data collection about non-residential buildings was managed by the Joint Research Centre of the European Commission and it has been operational in European Member States as well as European Economic Area countries [7].

Energy consumptions in shopping malls are primarily based on guaranteeing a comfortable environment for customers and heating, cooling and ventilation systems are one of the main causes of energy use in shopping centers. [8].

Energy savings can be obtained by means of the adoption of different efficient technological measures and several among these concerns the HVAC system.

In particular, a feature of commercial mall is that, in order to preserve the thermal comfort conditions, it could happen some zones have to be cooled also during the middle and the winter seasons. In fact, cooling requirement must balance internal gains due to occupancy, lighting, electrical devices, 
and solar radiation entering through the large skylights.

A typical cooling plant system in commercial buildings consists of fan coil units fed with water coming from an air conditioning system based on mechanical vapor compression. This air conditioning system needs a significant amount of electricity. The most widely used refrigeration plant for these buildings is a water-cooled condensers system, that uses recirculation water from cooling towers. In these systems, water leaves the water-cooled condenser and enters the top of the cooling tower, where it is sprayed over the fills and cooled to a lower temperature by means of evaporation. Thereafter it is supplied to the water-cooled condenser again.

A different cooling plant configuration contemplates coupling a vapour compression chiller with a forced drycooler condenser.

A significant advantage in realizing the condensing process by means dry coolers is that, when the weather conditions are suitable, water cooled by dry-coolers can be directly supplied to fan-coils, without using the chiller and achieving a free-cooling.

In a previous study [9] authors evaluated the feasibility and the advantages to substitute cooling towers for dry-coolers. For different locations, TRNSYS simulations were carried out and the results shown that, in cities with a colder climate, there is a greater energy saving due to a lower value of the external mean air temperature; in particular, the city with the greatest annual energy saving amount (42.4\%) is Hamburg, whereas the city with the lowest annual energy saving amount $(14.2 \%)$ is Messina.

It is important to find a strategy more efficient in hot climates, where the periods suitable for free-cooling are shorter.

In that climates, a way to improve the overall performance of a cooling system and to reduce energy consumptions could be the realization of an evaporative cooling process.

In fact, in a previous work [10] about the ability of different plant configurations to improve indoor thermal conditions in industrial building, the same authors found that, the mechanical ventilation system allow an amount of energy saving, in cold cities (Prague, Hamburg) about equal to 50\%, and in hot cities lower than $10 \%$, whereas the direct and indirect evaporative cooling systems allow an energy saving around $50 \%$ and $40 \%$ for all considered locations respectively.

With reference to the evaporative cooling pad, an analysis of several studies from the literature highlighted that in most cases the studies are experimental investigations about the influence of several parameters on the evaporative pad performance. Sohani et al. [11] proposed three model, i.e. artificial network, genetic programming and multiple linear regression to predict the overall performances of an evaporative cellulose pad.

Malli et al. [12] tested in a sub sonic wind tunnel two samples of cellulosic pad and found that effectiveness and humidity variation decrease by increasing inlet air velocity.

Moreover, there are a lot of studies, which has been carried out about the improvement of a cooling plant performance as results of the insertion of an evaporative cooling pad.

An experimental study [13] has carried out in order to investigate the impact of different cooling pads on the performance of an air-conditioning system in Spain; the authors found that the compression power consumption is reduced by $11.4 \%$, the cooling capacity is increased by $1.8 \%$ and the overall COP is increased by $10.6 \%$.
Wang et al. [14] carried out an experimental investigation of the COP's increase of an air conditioning plant equipped with an evaporative cooling condenser; the authors evaluated in addition to others parameters a power reduction up to $14.3 \%$ on the compressor.

Islam et al. [15] analyzed experimentally and numerically the performance of an air-conditioning unit equipped with an evaporative-cooled condenser unit and found that, thanks to the insertion of the latter, the coefficient of performance (COP) of the plant increases by about $28 \%$.

The effect of different cooling pads on the overall performance of an air conditioning system is experimentally evaluated by Martinez et al. [16] with the aim to identify the thickness of the pad that maximize the COP of the system; it is found an optimal thickness of $100 \mathrm{~mm}$, which allows an about $10.6 \%$ of COP increasing.

In a review paper Vakiloroaya et al. [17] studied the ability of different approaches to increase the efficiency of HVAC systems in order to obtain an HVAC energy saving. They proposed a hybrid evaporative cooling system in order to reduce the temperature of the outside air and compared the results with measured data of an existing central cooling plan of a commercial building: the proposed system allows an energy saving potential up to $52 \%$ [18].

Other authors [19] combined a central cooling plant with a regenerative evaporative cooling system and they evaluated an electrical energy saving amount about $15.7 \%$.

A combined experimental plant consisting of an IEC unit and a packaged unit air conditioner was realized and tested by Delfani et al. [20]; they found a reduction in cooling load up to $75 \%$ and a reduction in electrical energy consumption around $55 \%$ during cooling season.

Previous studies [21], carried out by the same authors, have evaluated the possible energy savings achievable by means of dry coolers adoption in heating and cooling plants serving office buildings.

In this work the aim is an evaluation of the energy saving reachable in a shopping mall when an evaporative cooling equipment is integrated with a dry cooler. The behavior of that cooling plant is simulated by means of TRNSYS simulations comparing the results, in terms of electrical energy saving, with those of a cooling plant without the evaporative pad.

A typical shopping mall has been modeled and several locations corresponding to northern, central and southern European cities has been considered.

\section{REFERENCE BUILDING MODEI}

Starting from a survey of the existing shopping malls in the main European cities, a building model has been identified.

The building is a rectangular double floor building with a gross floor area of $20000 \mathrm{~m}^{2}$ and a height of $4 \mathrm{~m}$. The total volume is $160000 \mathrm{~m}^{3}$. A shed roof with 12 vertical skylights, $0.70 \times 2.5 \mathrm{~m}$, has been chosen. The longer edge of building is oriented along north-south axis and the entrance glass doors are on two shorter edges.

The internal layout of each floor is shown in Fig. 1-a, where it can see that shops take up perimeter and core zones and occupy $60 \%$ of the total floor area, leaving $40 \%$ of the floor area to a common zone in order to allow a suitable space for the flow of people during the peak time. 
In order to take into account there are zones which different expositions and because the relevant dimension of building, different thermal zones, with the same internal load and the same heat losses through wall, were set. In Fig. 1 different zones are summarized and are identified by means a number.

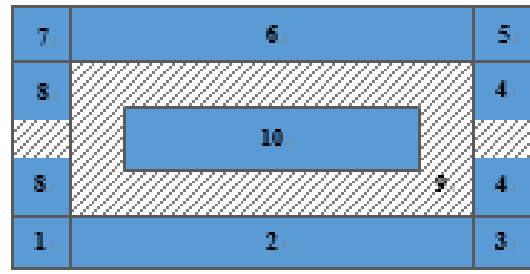

shops zone.1

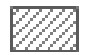

common zove.।

Figure 1. Floor plan for the simulated building with using destination and thermal zones

The model of the building, shown in Figure 2, was created with TRNBuild module.

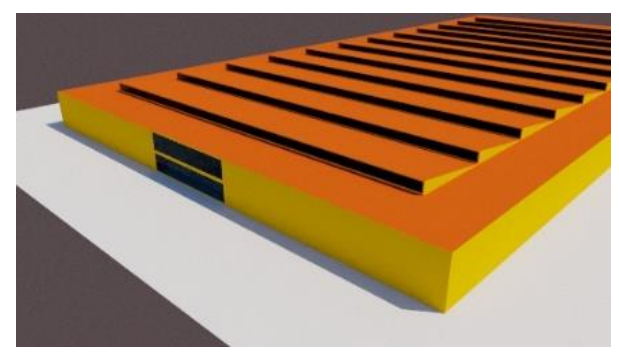

Figure 2. Sketch of the simulated commercial mall

The building elements properties were summarized in Table 1.

Table 1. Building elements construction details

\begin{tabular}{cc}
\hline Element & $\mathrm{U}\left[\mathrm{W} / \mathrm{m}^{2} \mathrm{~K}\right]$ \\
\hline Exterior wall & 0.351 \\
\hline Inner wall & 0.456 \\
\hline Ground floor & 0.340 \\
\hline Roof & 0.283 \\
\hline Window & 5.8 \\
\hline
\end{tabular}

The amount of electrical equipment loads according to ASHRAE Standard guidelines was set at $30 \mathrm{~W} / \mathrm{m}^{2}$ and was split in a radiative part $(30 \%)$ and a convective part (70\%).
Thermal load of electrical equipment was calculated as product of electrical power, interval time and a coefficient depending on the day of the week; the coefficient was set to 1 during opening hours and to 0.2 during closing hours in order to account for stand-by conditions.

Inside common zones, where there are skylights, windows or entrance doors, an infiltration rate equal to $0.5 \mathrm{ACH}$ (Air Changes per Hour) was set.

Sensible and latent heat loads from people depend on their activity and, according to ISO7730, assuming a light activity for shopping mall, a load of $185 \mathrm{~W}$ for each person (90 sensible and 95 latent) has been considered.

With regard to the number of people inside shopping mall, based on UNI10339-2014, a design value of crowding index equal to 0,2 person $/ \mathrm{m}^{2}$ both sale zone and common zone has been chosen. That value was scaled down depending on daily and weekly schedule of occupant's presence.

\section{COOLING PLANT SYSTEMS}

The behaviour of two different cooling plant configurations has been evaluated and compared with traditional cooling systems. The two configurations are: a chiller equipped with a dry cooler C-DC and a chiller equipped with a dry cooler and an evaporative cooling pad CE-DC.

In the first configuration the Dry-Cooler can work as condenser of the vapor compression chiller (Fig. 3-a) or, under suitable conditions, achieving a free cooling (Fig. 3-b).

The second cooling plant system is analogous to first one but with an evaporative cooling pad has been supposed before upstream the dry cooler with the aim to decrease the temperature of the air flow entering the dry cooler (Fig. 3-c, Fig. 3-d).

Simulations of the first configuration are carried out by the authors in a previous work [9]. The investigated cooling system has been compared, in terms of energy consumption and overall coefficient of performance, with a configuration most widely used for commercial building, in which the water-cooled condensers of the chiller uses recirculation water from a cooling tower. Results of that study showed that the proposed system is not so advantageous in hot climate.

Following what has been noted in the previous study, a system suitable for hot climate has been searched identifying a configuration in which the dry cooler is equipped with an evaporative pad

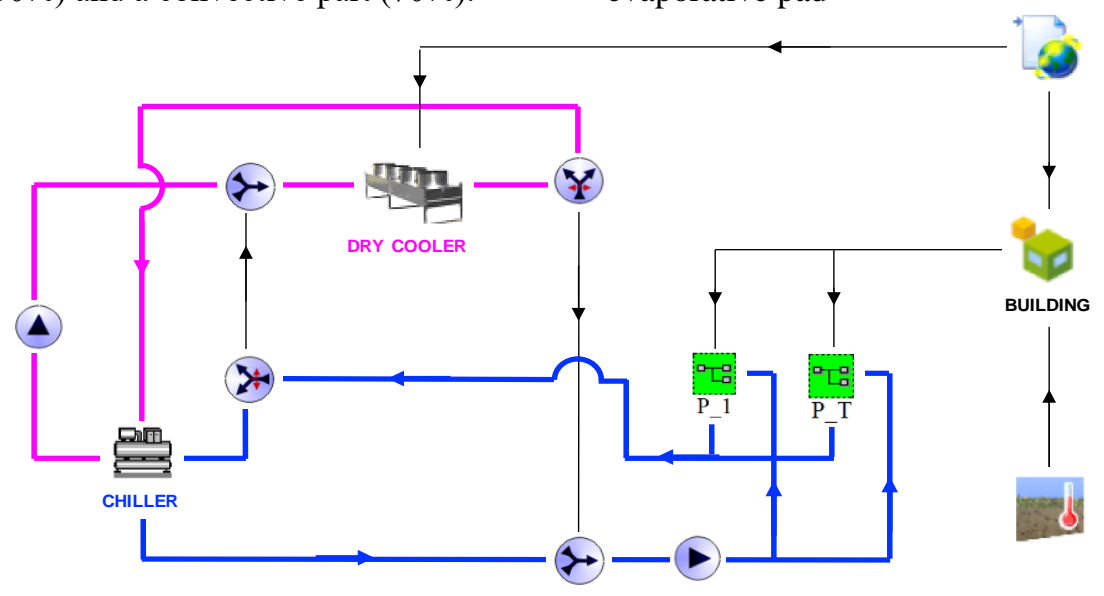

Figure 3-a. Schematic layout of the C-DC system, where Dry-Cooler works as condenser (magenta line) and water is cooled by chiller (blue line) 


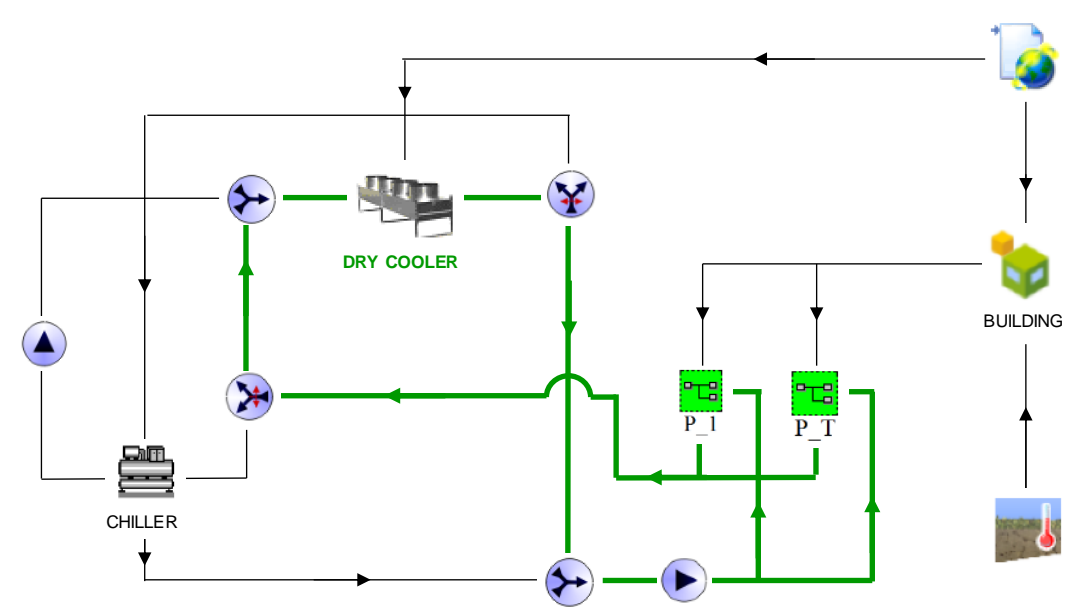

Figure 3-b. Schematic layout of the C-DC system, where Dry-Cooler allows a free cooling mode (green line)

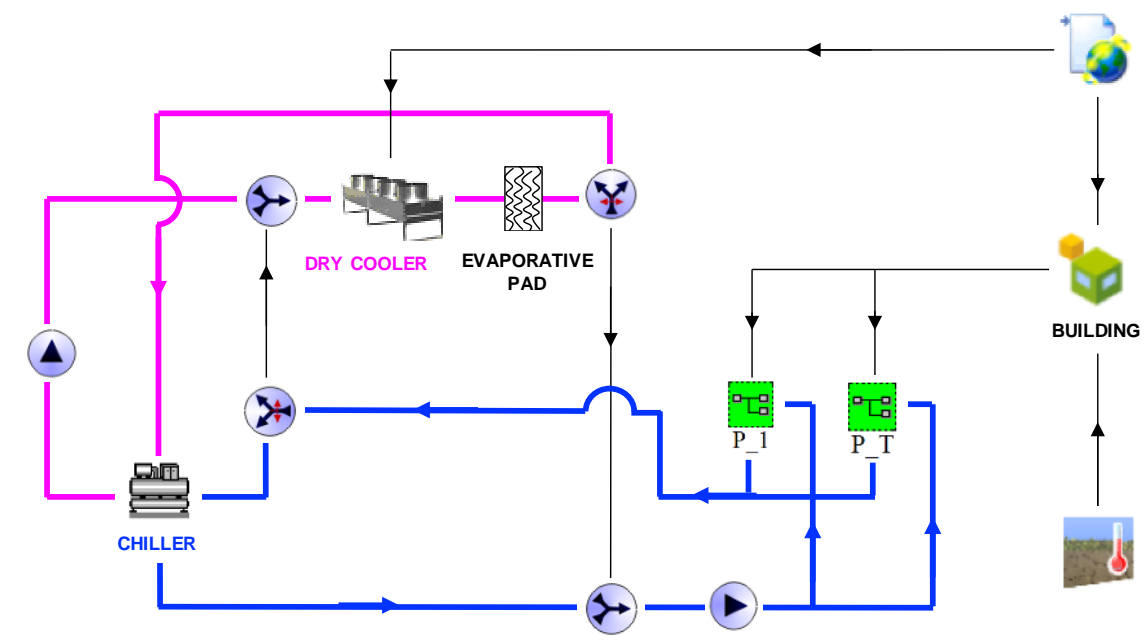

Figure 3-c. Schematic layout of the C-E-DC system, where Dry-Cooler works as condenser (magenta line) and water is cooled by chiller (blue line)

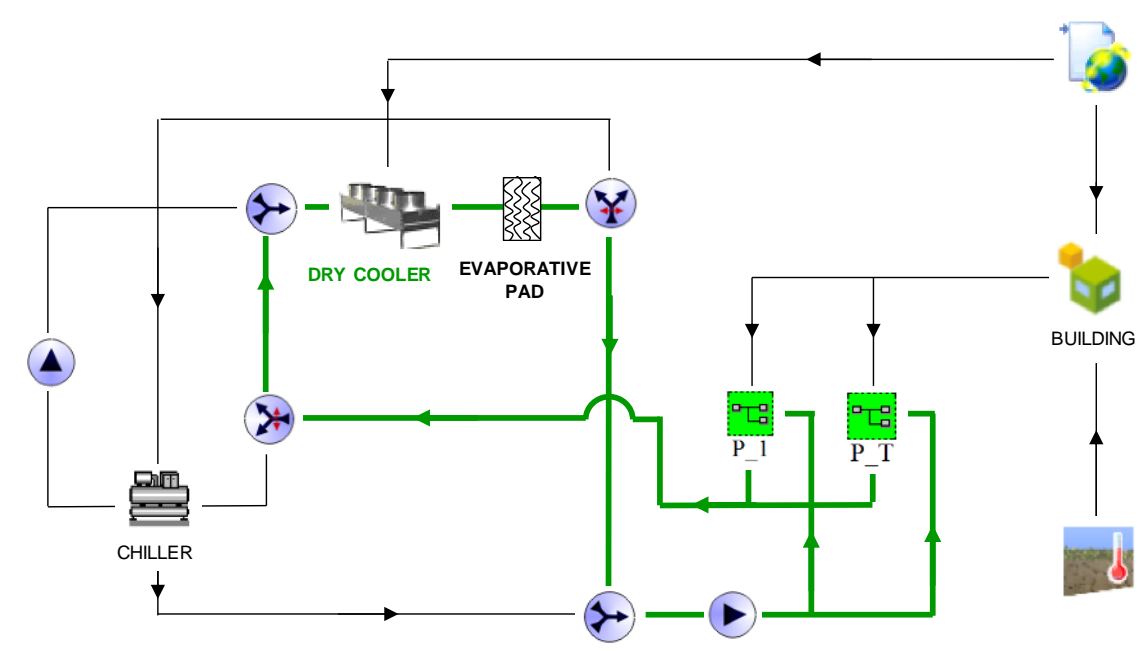

Figure 3-d. Schematic layout of the C-E-DC system, where Dry-Cooler allows a free cooling mode (green line)

\subsection{Mode of operation}

The C-DC and C-E-DC configurations have been obtained substituting cooling towers, usually coupled with a chiller in traditional cooling plant, for Dry-Coolers.

The main advantage of this solution is that, when the weather conditions are suitable, water cooled by Dry-Coolers can be directly supplied to fan-coils, without using the chiller.
In Fig. 4 a flow diagram describes the mode of operation of the cooling plant.

A control system is necessary to deviate the water to cool down from the Dry-Cooler to the Chiller and vice versa by turning a three-way valve. In order to choose between the Chiller and the Dry-Cooler, the control system checks the values of the internal and external air temperature.

In particular, the conditions, under which, C-DC cooling 
plant works in free cooling mode are:

- fan-coils have to be switched on: this happens when the room thermostat exceeds $25^{\circ} \mathrm{C}$ and when the shopping mall is open;

- temperature difference between internal air and external air have to be greater than $10 \mathrm{~K}$; that condition takes into account that the water have to pass through two heat exchangers and that disadvantage in terms of efficiency is acceptable if the gradient temperature is greater than $10 \mathrm{~K}$;

- internal air temperature has to be lower than $28^{\circ} \mathrm{C}$, otherwise the chiller has to switch on.

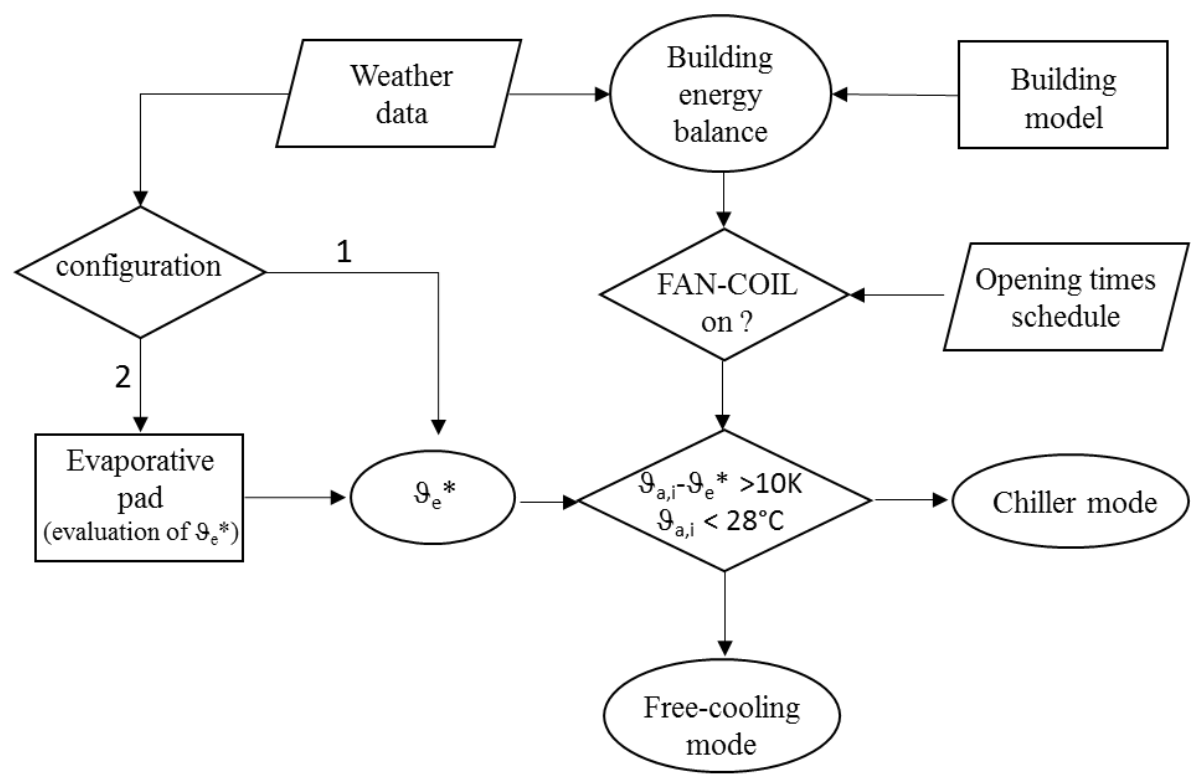

Figure 4. Flow diagram of the operation mode of the C-DC system

The operation conditions under which works the C-E-DC system are the same of the C-DC system above reported, with just a difference in the second condition, that concern the temperature gradient between internal air and air exiting from evaporative cooling pad.

In each floor of the commercial building 10 different thermal zones are modeled, nine of which are equipped with a cooling equipment, whereas in the aisle zone for the flow of people, there is not any cooling device; therefore 18 fan coil units are implemented in TRNSYS model.

Since zones have different expositions, could happen that only few or only one zone requires a cooling load. Having modeled 18 different cooling terminal devices, the cooling plant works even if only one zone thermostat sends the signal.

In order to simplify the analysis, only one fan coil for each zone is been considered, with a cooling capacity equal to cooling requirements of the whole zone.

In the TRNSYS model, a schedule type has been inserted to take into account for opening times and days; that schedule is necessary to establish hours during which the cooling plant have to be on and also to activate internal gains due to people and lights.

In order to carry out more realistic simulations, a survey of the existing shopping malls in the main European cities with their opening times were considered. The cities considered in the survey are that chosen for the simulations.

\section{EVAPORATIVE COOLING DEVICE}

In order to obtain an evaporative cooling of the air flow entering dry cooler, a cellulosic evaporative pad has been chosen, that is composed of corrugated papers staggered glued.

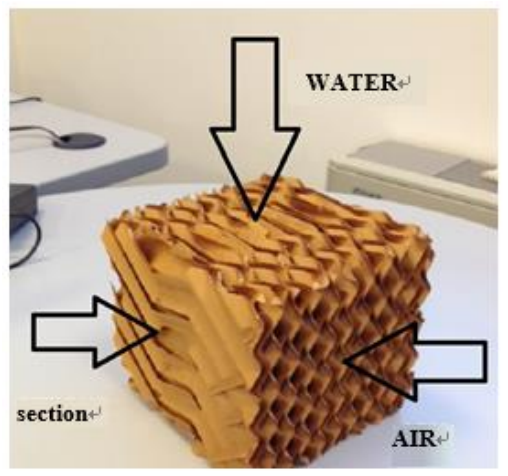

Figure 5. Configuration of cellulosic pad

In Fig. 5 a part of the investigated pad is shown, where two arrows highlight the way of the water flow, which damps the pad, and the way of the air flow, which has to be cooled.

The section of the air flow channels formed by the staggered layers of cellulosic is shown in Fig. 6.

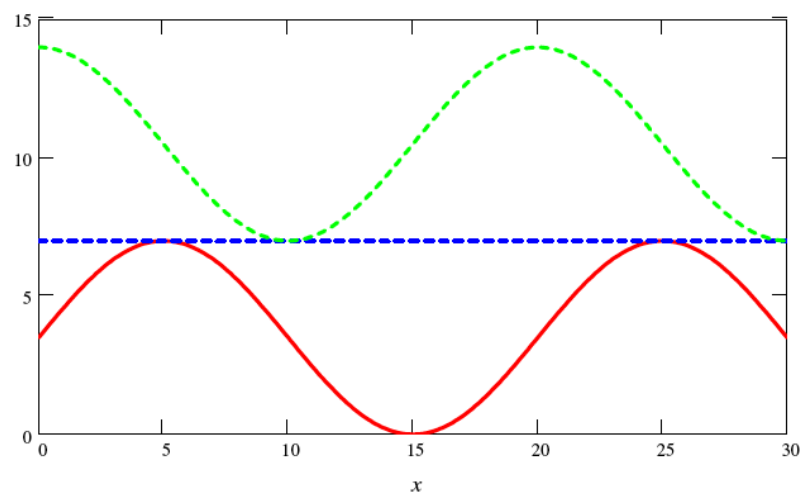

Figure 6. A section of the air flow channel 
It can be noted that the, even if the relative position of the two sinusoids varies the perimeter length of the basic module is constant.

A section perimeter, expressed in $\mathrm{mm}$, can be evaluated by the following expression:

$P=2 \int_{0}^{20} \sqrt{1+\left(\frac{3,5 \pi}{10}\right)^{2} \cos ^{2}\left(\frac{x \pi}{10}\right)} d x=50.2$

For the previous formula the dimensions can be taken from Fig.CC. The maximum cross flow area is:

$$
A=3,5 \cdot 4 \int_{0}^{10} \sin \left(\frac{x \pi}{10}\right) d x=89.1
$$

Based on eq. 2, the number of channels per unit pad area $n_{c h}$ and the average area of the flow section $A_{m}$ can be calculated respectively as:

$n_{c h}=\frac{1}{A}=11220$

$A_{m}=\frac{1,5 A}{2}=66.8$

Therefore, the hydraulic diameter of the channels is:

$d_{h}=\frac{4 A_{m}}{P}=5.3$

The conditions of the air outgoing the evaporative pad can be evaluated with different approximation levels. A first level is based on experimental correlations available in literature; these correlations allow to evaluate humidity and temperature values of the outlet air exploiting the analogy between heat and mass transfer.

\subsection{Performance parameters of the evaporative pad}

Correlations are based on dimensionless numbers, so it is necessary the identification of the flow regime.

The length of the air path inside evaporative pads is to short in order that the flow field is completely developed. Therefore, there is a laminar flow regime, and it can be described by means of the Sieder and Tate experimental correlation, that, in case of small viscosity changes, is the following:

$$
\mathrm{Nu}=1.86\left(\operatorname{RePr} \frac{d_{h}}{L}\right)^{1 / 3}
$$

where $\mathrm{Nu}$ is Nusselt number, Re is Reynolds number, Pr is Prandtl number, dh and $\mathrm{L}$ are the hydraulic diameter and the lenght of the air way respectively.

Starting from Nusselt number, the convective heat transfer coefficient can be evaluated as:

$h=\frac{\mathrm{Nu} \lambda}{d_{h}}$ where, lambda is the air thermal conductivity.

Thanks to the similarity between thermal and moisture exchanges, the same correlation can be used to evaluate the Sherwood number:

$\operatorname{Sh}=1.86\left(\operatorname{ReSc} \frac{d_{h}}{L}\right)^{1 / 3}$

where $S c$ is the Schmidt number given by:

$\mathrm{Sc}=\frac{v}{D_{w a}}$

Starting from Sherwood number, the average moisture transfer coefficient $h_{m}$ can be evaluated as:

$h_{m}=\frac{\operatorname{Sh} D_{w a}}{d_{h}}$

where $D_{w a}=., 6 \cdot 10^{-5} \mathrm{~m}^{2} / \mathrm{s}$ is the diffusion coefficient vapor in air.

As an example, in Table 2 values of the dimensionless numbers describing the phenomenon are reported with reference to certain conditions.

Table 2. Dimensionless number under certain conditions

\begin{tabular}{ccc}
\hline Physical property & & u.m. \\
\hline Air velocity & 2.08 & $\mathrm{~m} / \mathrm{s}$ \\
\hline Inlet air temperature & 25.03 & ${ }^{\circ} \mathrm{C}$ \\
\hline Percentage air humidity & 56.6 & $\%$ \\
\hline Vapour pressure & 1790 & $\mathrm{~Pa}$ \\
\hline Air pressure & 98050 & $\mathrm{~Pa}$ \\
\hline Humidity ratio & 11.57 & $\mathrm{~g}_{\mathrm{v}} / \mathrm{kg}_{\mathrm{a}}$ \\
\hline & & \\
\hline $\mathrm{Re}$ & 706 & \\
\hline $\mathrm{Sc}$ & 0.604 & \\
\hline $\mathrm{Sh}$ & 4.33 & \\
\hline $\mathrm{h}_{\mathrm{m}}$ & 0.021 & $\mathrm{~m} / \mathrm{s}$ \\
\hline
\end{tabular}

In order to simplify the analytical characterisation of the evaporative pad, it has supposed that, at the end of phenomenon, its temperature matches the inlet air wet bulb temperature. The amount of evaporating water depends proportionally on the difference of the water vapour concentration between pad surface and flowing air; that difference has the maximiun value at the entrance of the pad and decreases, with exponential law, toward the exiting section.

Vapour mass fraction of the air at the end of the evaporative pad can be expressed as:

$\omega_{o}=\omega_{i n}+\left(\omega_{s}-\omega_{i n}\right) \exp \left(-\frac{P L}{A} \frac{h_{m}}{w}\right)$

and the amount of the evaporated water per square meter of the pad front section is:

$\dot{m}_{e v}=\rho w\left(\omega_{o}-\omega_{i n}\right)$

and the corresponding heat flux extract to the air is: 
$q \sim \dot{m}_{e v} r$

The humidity ratio and the specific enthalpy of the outgoing air are:

$$
\begin{aligned}
& x_{o}=x_{i n}+\frac{\dot{m}_{e v}}{\dot{m}_{a}} \\
& e_{o}=e_{i n}-\frac{q}{\dot{m}_{a}}
\end{aligned}
$$

The outgoing air temperature becomes:

$$
t_{o}=\frac{e_{o}-x_{o} r_{0}}{c_{p a}+x_{0} c_{p v}}
$$

That air temperature value is significantly lower than the temperature value of the air at the entrance of evaporative pad.

\section{SIMULATIONS}

Dynamic simulation of commercial mall using three different cooling plant configurations is carried out in TRNSYS software on hourly basis.

The two different systems modeled are:

- C-DC system: cooling plant with a chiller equipped with a dry cooler, that can be used as condenser of refrigeration system or to work with free-cooling mode, if the external weather conditions are suitable;

- C-E-DC system: the previous system equipped with an evaporative cooling pad upstream the dry cooler in order to enlarge the range of temperatures suitable for free cooling.

TRNSYS performs cooling load calculations with transfer function method by using weather and building information data. Simulations were carried out using an ideal air conditioning system, assuming set points for cooling and heating $26^{\circ} \mathrm{C}$ and $20^{\circ} \mathrm{C}$ respectively.

The TRNSYS model has been implemented using the following type:

- Building (Type 56)

- Weather data (Type 15-3)

- Fan coil (Type 600)

- Chiller (Type 666)

- Dry Cooler (Type 511)

- Cooling Tower

Different climatic conditions are investigated considering different European cities:

- Amsterdam (Nederland)

- Hambug (Germany)

- Graz (Osterreich)

- Frankfurt (Germany)

- Prague (Poland)

- Porto (Spain)

- Genevre (France)

- Torino (Italia)

- Barcellona (Spain)

- Brindisi (Italia)

- Ankara (Turkey)

- Messina (Italia)

- Damasco (Syria)

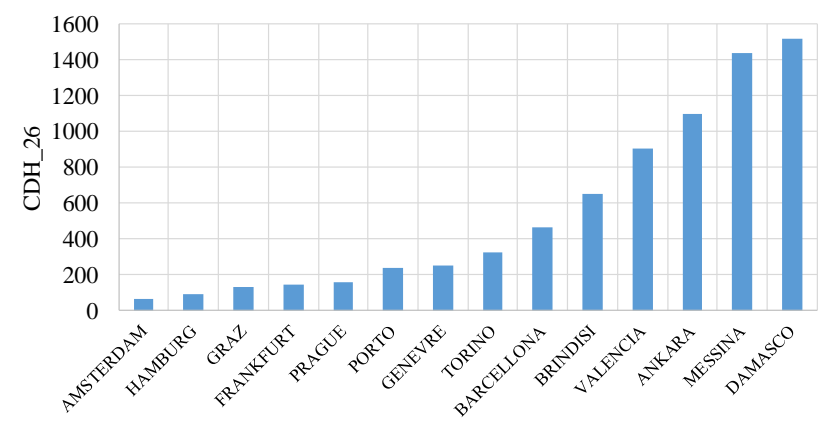

Figure 7. $C D H \_26$ for the different European cities considered in simulations

As parameter to choose cities, covering a large range of different weather data, is the Cooling Degree-Hours, Base $\vartheta_{0}$ $\left(C D H \_\vartheta_{0}\right)$; that index is proposed by ASHRAE [9bis] and is defined as:

$C D H_{-} \vartheta_{0}=\sum_{j=1}^{N}\left(\vartheta_{e}-\vartheta_{0}\right) \quad$ for $\quad \vartheta_{e}-\vartheta_{0}>0$

where $\vartheta_{e}$ is the hourly dry bulb temperature, $\mathrm{N}$ is the number of hours for entire year and $\vartheta_{0}$ is the base temperature.

According to the design value of the internal air temperature, suggested by International Standards [10] for the summer period, a base temperature equal to $26^{\circ} \mathrm{C}$ has been used to evaluate the parameter $C D H \_26$. Fig. 7 shows the $\mathrm{CDH}_{-} 26$ for the different cities considered.

\subsection{Energy saving evaluation}

In a previous work authors have highlighted the energy saving due to the introduction of a dry cooler instead a cooling tower in a refrigeration plant. Simulations results showed that in cities with a colder climate, there is a greater energy saving due to a lower value of the external mean air temperature.

In order to increase the possibility of free cooling in cities, where the climate is hot or moderate, authors proposed the addition of an evaporative cooling pad to the refrigeration plant.

Results of simulations show a performance improvement of the cooling plant in all cities considered. The comparison between energy savings obtained with two plant configurations, with and without evaporative pad, has been reported in Fig. 8.

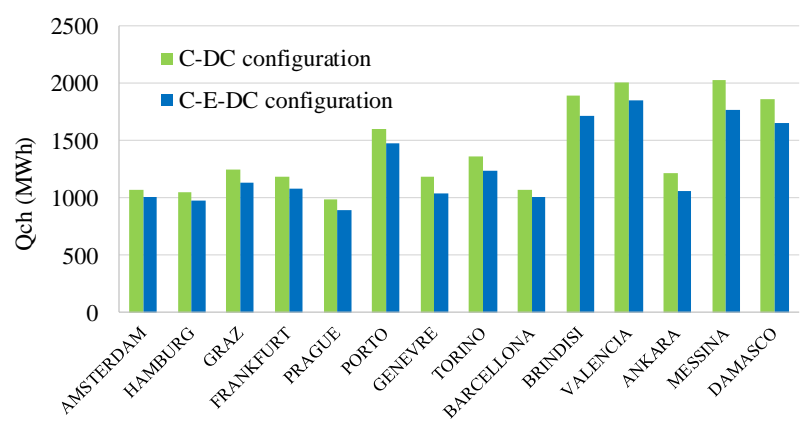

Figure 8. Comparison of the chiller energy consumption in two plant configurations: C-DC system and C-E-DC system, for the considered locations 
The energy saving is obtained thanks to two effects; the first effect is the reduction of the air temperature entering in dry cooler, due to the water evaporation inside the evaporative pad. Thanks to that temperature decrease, cooling plant can work in free cooling mode for a number of hours greater than when the evaporative pad is absent, as can be seen in Fig. 9.

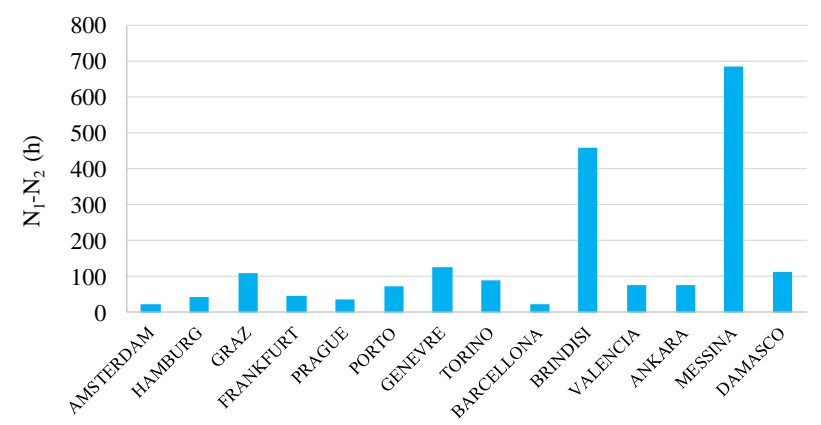

Figure 9. Comparison of the free cooling mode hours in two plant configurations: C-DC system and C-E-DC system, for the considered locations

There is also another effect, that concerns the performance of the chiller. The chiller has been modeled by means of TRNSYS Type 666, which allows to take into account the influence of external climatic conditions over the chiller performance. Figure 10 shows the variation of EER values for different chilled water temperatures, varying the cooling water temperature.

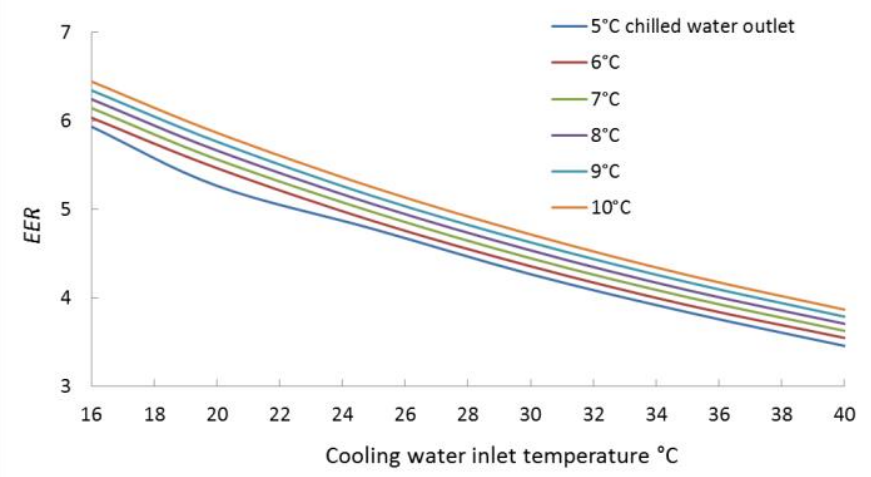

Figure 10. EER trend over cooling water inlet temperature for different outlet temperatures of the chilled water

When the external air temperature is too high, dry cooler works as condenser for the chiller, and the presence of the evaporative pad allows to reduce the cooling water temperature of the chiller increasing in that way its performance.

Finally, it was looking for a correlation between the amount of energy saving and the climate of considered location. To characterize the climate of the locations, the $\mathrm{CDH}$ has been chosen and in Fig. 11 it can be see the influence of the weather conditions on the ability of the evaporative pad to save electrical energy of the chiller and increase the overall performance of the cooling plant.

Energy saving shows a linear dependence with the cooling degrees hours, also if the index correlation is a little low. In order to find a better correlation between climate and energy saving, another parameter, which takes into account also the humidity of the location, could be defined. In fact, the cooling degrees hours parameter is evaluated basing on the dry bulb temperature.

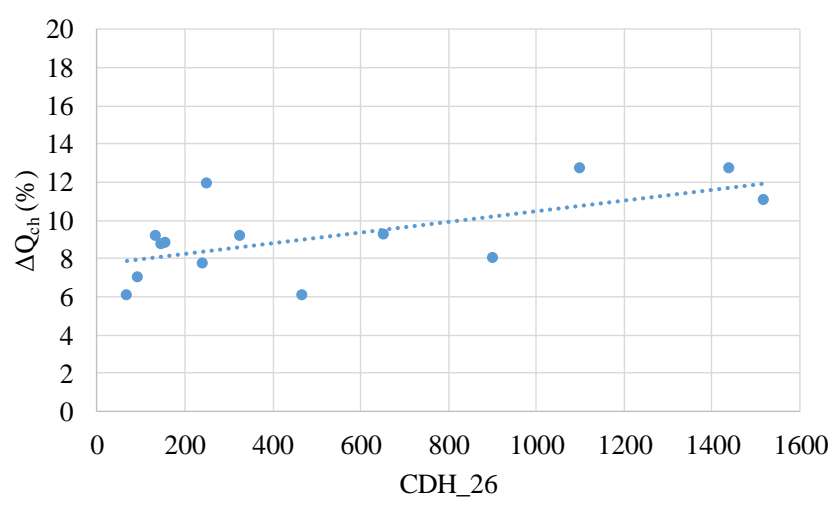

Figure 11. Percentage reduction of the chiller electrical energy consumptions vs CDH_26 for the considered locations

\section{CONCLUSIONS}

This work arises from a previous study about the advantages, in terms of energy saving, achievable by means of the integration of an indirect free cooling system in a traditional cooling plant used for a shopping center cooling.

The aim of this study was the overall performance improvement of the cooling plant previously analyzed adding a new equipment: an evaporative cooling pad.

In particular, two different cooling plant configurations has been investigated: C-DC and C-E-DC configurations.

The C-DC configuration, object of analysis in the previous work, a chiller is equipped with a dry cooler with the aim to use the dry cooler alternatively to cool down the refrigerant flow, or the water supplied to fan coils, achieving in such a way an indirect free cooling. If there are suitable weather conditions, the proposed system allows to turn off the chiller and allows to save electrical energy.

The C-E-DC configuration is obtained adding a cooling evaporative pad upstream the dry cooler in order to enlarge the range of temperatures suitable for free cooling. In fact, while the external air flows through the evaporative pad, the water with which the pad is wet, evaporates and extracts latent heat of evaporation from the external air flow, reducing its temperature.

The performance of two plant configurations has been investigated by means of TRNSYS simulations. A building model of a typical shopping mall has been modeled and several European cities has been considered.

Simulation results show that the C-E-DC configuration allows a greater energy saving amount than C-DC configuration for all the cities considered.

It can be noted that is a linear correlation between the climate and the electrical energy saving. In particular, the locations with a hot or moderate climate have a higher reduction in chiller electrical consumptions.

Further investigations will be carried out taking in to account more extensively the moisture content of the air for the different locations considered. 


\section{RFERENCES}

[1] D'Agostino D., Cuniberti B., Bertoldi P. (2017). Energy consumption and efficiency technology measures in European non-residential buildings, Energy and Buildings, Vol. 153, pp. 72-86. DOI: 10.1016/j.enbuild.2017.07.062

[2] D'Agostino D., Zangheri P., Castellazzi L. (2017). Towards Nearly Zero Energy Buildings (NZEBs) in Europe: A focus on retrofit in non-residential buildings, Energies, Vol 10, p. 117. DOI: $\underline{10.3390 / \mathrm{en} 10010117}$

[3] D'Agostino D. (2015). Assessment of the progress towards the establishment of definitions of Nearly Zero Energy Buildings (NZEBs) in European Member States, J. Build. Eng., DOI: 10.1016/j.jobe.2015

[4] Zebra 2020, Nearly zero energy building strategy 2020- Strategies for a nearly Zero-Energy Building market transition in the European Union.

[5] BPIE Europe's Buildings Under the Microscope (2011)

[6] Cortella G., Lollini R., Noris F., D'Agaro P., Saro O. (2014). CommONEnergy: Re-conceptualizing shopping malls from consumerism to energy conservation, Refrigeration Science and Technology. Science Et Technique Du Froid, Vol. 2014, pp. 582589.

[7] Valentová M., Bertoldi P. (2011). Evaluation of the green building programme, Energy Build, Vol. 43, pp. 1875-1883.

[8] Bointner R., Toleikyte A., Woods R., Atanasiu B., De Ferrari A., Farinea C., Noris F. (2013). Shopping malls features in EU-28 + Norway, Deliverable 2.1 for CommONEnergy FP7-2013-NMP-ENV-EeB.

[9] De Angelis A., Ceccotti L., Saro O. (2017). Energy savings evaluation for dry-cooler equipped plants in shopping mall buildings, International Journal of Heat and Technology, Vol. 35, No. Special Issue 1, pp. S361-S366. DOI: 10.18280/ijht.35Sp0149

[10] De Angelis A., Saro O., Truant M. (2017). Evaporative cooling systems to improve internal comfort in industrial buildings, Energy Procedia, Vol. 126, pp. 313-320. DOI: 10.1016/j.egypro.2017.08.245

[11] Sohani A., Zabihigivi M., Moradi M.H., Sayyaadi H., Balyani H.H. (2017). A comprehensive performance investigation of cellulose evaporative cooling pad systems using predictive approaches, Applied Thermal Engineering, Vol. 110, pp. 1589-1608.

[12] Malli A., Seyf H.R., Layeghi M., Sharifian S., Behravesh H. (2011). Investigating the performance of cellulosic evaporative cooling pads, Energy Conversion and Management, Vol. 52, pp. 2598-2603.

[13] Martinez P., Ruiz J., Cutillas C.G., Martinez P.J., Kaiser A.S., Lucas M. (2016). Experimental study on energy performance of a split air-conditioner by using variable thickness evaporative cooling pads coupled to the condenser, Applied Thermal Engineering, Vol. 105, pp. 1041-1050.

[14] Wang T., Sheng C., Agwu Nnanna A.G. (2014). Experimental investigation of air conditioning system using evaporative cooling condenser, Energy and Buildings, Vol. 81, pp. 435-443.

[15] Islam M.R., Jahangeer K.A., Chua K.J. (2015). Experimental and numerical study of an evaporatively-

cooled condenser of air-conditioning systems, Energy, Vol. 87, pp. 390-399.

[16] Martinez P., Ruiz J., Cutillas C.G., Martinez P.J., Kaiser A.S., Lucas M. (2016). Experimental study on energy performance of a split air-conditioner by using variable thickness evaporative cooling pads coupled to the condenser, Applied Thermal Engineering, Vol. 105, pp. 1041-1050.

[17] Vakiloroaya V., Samali B., Fakhar A., Pishghadam K. (2014). A review of different strategies for HVAC energy saving, Energy Conversion and Management, Vol. 77, pp. 738-754. DOI: 10.1016/j.enconman.2013.10.023

[18] Vakiloroaya V., Khatibi M., Ha Q.P., Samali B. (2011). New integrated hybrid evaporative cooling system for HVAC energy efficiency improvement, IEEE/SICE International Symposium on System Integration, Kyoto, Japan, pp 591-596. DOI: 10.1109/SII.2011.6147546

[19] Khandelwal A., Talukdar P., Jain S. (2011). Energy savings in a building using regenerative evaporative cooling, Energy Build, Vol. 43, pp. 581-591. DOI: 10.1016/j.enbuild.2010.10.026

[20] Delfani S., Esmaeelian J., Pasdarshahri H., Karami M. (2010). Energy saving potential of an indirect evaporative cooler as a pre-cooling unit for mechanical cooling systems in Iran, Energy and Buildings, Vol. 42, pp 2169-2176. DOI: 10.1016/j.enbuild.2010.07.009

[21] De Angelis A., Ceccotti L., Saro O. (2016). Cooling energy savings with dry-cooler equipped plants in office buildings, International Journal of Heat and Technology, Vol. 34, No. Special Issue 2, pp. S205S211. DOI: 10.18280/ijht.34S203

[22] De Angelis A., Ceccotti L., Saro O. (2016). Cooling energy savings with dry-cooler equipped plants in office buildings, International Journal of Heat and Technology, Vol. 34, No. Special Issue 2, pp. S205S211. DOI: $10.18280 /$ ijht.34S203

[23] De Angelis A., Medici M., Saro O., Lorenzini G. (2015). Evaluation of evaporative cooling systems in industrial buildings, International Journal of Heat and Technology, Vol. 33, No. 3, pp. 1-10.

\section{NOMENCLATURE}

A

$\mathrm{c}_{\mathrm{p}}$

d

e

$\mathrm{h}$

n

$\mathrm{N}$

$\mathrm{P}$

Q

$\mathrm{Nu}$

$\operatorname{Pr}$

$\mathrm{Re}$

$\mathrm{Sc}$

$\mathrm{Sh}$

$\mathrm{X}$

U

$\vartheta$ area, $\mathrm{m}^{2}$

specific heat capacity, $\mathrm{kJ} / \mathrm{kgK}$

diameter, $m$

specific enthalpy, $\mathrm{J} / \mathrm{kg}$

heat transfer coefficient, $\mathrm{W} / \mathrm{m}^{2} \mathrm{~K}$

number

number of hours, $\mathrm{h}$

perimeter, $\mathrm{m}$

electrical energy, Wh

Nusselt number (dimensionless)

Prandtl number (dimensionless)

Reynolds number (dimensionless)

Schmidt number (dimensionless)

Sherwood number (dimensionless)

humidity ratio

thermal transmittance, $\mathrm{W} / \mathrm{m}^{2} \mathrm{~K}$

temperature 
density, $\mathrm{kg} / \mathrm{m}^{3}$

thermal conductivity, $\mathrm{W} / \mathrm{mK}$

kinematic viscosity, $\mathrm{m}^{2} / \mathrm{s}$

\section{Subscripts}

air

e

external
W

ch

ev

$\mathrm{h}$

o

in water

chilled

chiller

evaporated

hydraulic

outlet

inlet 